\title{
Optimization of operation rule curves and flushing schedule in a reservoir
}

\author{
Fi-John Chang, ${ }^{1 *}$ Jihn-Sung $\mathrm{Lai}^{2}$ and Li-Shan $\mathrm{Kao}^{1}$ \\ ${ }^{1}$ Department of Bioenvironmental Systems Engineering and Hydrotech Research Institute, National Taiwan University, Roosevelt Road, \\ Taipei 10770, Taiwan, R.O.C. \\ ${ }^{2}$ Hydrotech Research Institute, National Taiwan University, Roosevelt Road, Taipei 10770, Taiwan, R.O.C.
}

\begin{abstract}
:
Flushing sediment through a reservoir has been practiced successfully and found to be inexpensive in many cases. However, the great amount of water consumed in the flushing operation might affect the water supply. To satisfy the water demand and water consumed in the flushing operation, two models combining the reservoir simulation model and the sediment flushing model are established. In the reservoir simulation model, the genetic algorithm (GA) is used to optimize and determine the flushing operation rule curves. The sediment-flushing model is developed to estimate the amount of the flushed sediment volume, and the simulated results update the elevation-storage curve, which can be taken into account in the reservoir simulation model. The models are successfully applied to the Tapu reservoir, which has faced serious sedimentation problems. Based on 36 years historical sequential data, the results show that (i) the simulated flushing operation rule curves model has superior performance, in terms of lower shortage index (SI) and higher flushing efficiency (FE), than that by the original reservoir operation; (ii) the rational and riskless flushing schedule for the Tapu reservoir is suggested to be set within an interval of every 2 or 4 years in the months of May or June. Copyright (C) 2003 John Wiley \& Sons, Ltd.
\end{abstract}

KEY WORDS genetic algorithm; reservoir simulation; operation rule curves; sediment flushing; flushing schedule

\section{INTRODUCTION}

For sustaining the long-term useful life of a reservoir, reservoir desiltation has received worldwide attention owing to the lack of suitable dam sites, the high cost of dam construction and strict environmental regulations. Additionally, in recent years a water reservoir has been considered as a non-renewable resource (Morris and Fan, 1998). In general, many measures of reservoir sedimentation control can be utilized to mitigate sediment deposits for reservoir desiltation, including reduction of incoming sediment yields from watersheds, mechanical removal by dredging or dry excavation, and hydraulic methods such as sediment flushing or density current venting. Among them, sediment flushing has been applied successfully and found to be effective as well as inexpensive in many cases (Shen and Lai, 1996).

Nevertheless, reservoir operators usually undertake the flushing operation by experience rather than a definite operation rule, especially in closing the gates of sluiceways to refill water. Moreover, flushing may not be necessary every year because the schedule for releasing sediment through the reservoir may increase the risk to water supply. For instance, the Gebidem reservoir in Switzerland was formed in 1968 by a 120-m-tall arch dam, which impounds only $9 \times 10^{6} \mathrm{~m}^{3}$ of water (Morris and Fan, 1998). If there had not been any flushing operation, it would have been filled up in about 20 years after dam completion. Prior to late summer flood every year, flushing has occurred between May and July since the dam was constructed. It has maintained the entire reservoir almost free from sedimentation because of its gorge-shaped reservoir geometry. Although * Correspondence to: Fi-John Chang, Department of Bioenvironmental Systems Engineering and Hydrotech Research Institute, National
Taiwan University, Roosevelt Road, Taipei 10770, Taiwan, R.O.C. E-mail: changfj@ccms.ntu.edu.tw 
the flushing operation is effective, a significant amount of sediment is flushed out of the reservoir. The high sediment concentration flow released may create a critical issue of downstream impacts on fishing, intake of water supply, etc.

In Taiwan, dramatic economic development and increasing population have resulted in a tremendous demand on water resources in the past several decades. Owing to non-uniform temporal/spatial distributions of precipitation and presence of high mountains with steep rivers all over the island, most of the runoff flows rapidly into the ocean and cannot be used directly as a stable source of water supply. In order to store the valuable natural resource, a water reservoir may be one of the most effective engineering means for water demand in Taiwan. However, the heavy rainfall intensity in monsoon seasons or during a typhoon usually generates a great amount of sediment yield from watersheds with steep-sloped mountains. There are 66 reservoirs in Taiwan, and two-thirds of them are classified small- or middle-sized reservoirs, with a storage capacity of less than $5 \times 10^{6} \mathrm{~m}^{3}$ (Chang and Lai, 1999). According to the official report of the reservoir sedimentation survey in 1996, reservoirs in Taiwan have been silted up and lost their gross capacity at a rate of approximately $0.5 \%$, i.e. about $14.6 \times 10^{6} \mathrm{~m}^{3}$ annually.

In Taiwan, only few reservoirs have conducted desilting operations by sediment flushing owing to lack of sediment release outlets. The Tapu reservoir, with initial storage capacity of $9.26 \times 10^{6} \mathrm{~m}^{3}$, was completed in 1960. However, from the data of the bed elevation survey in 1987, the cumulative deposits once filled up $51 \%$ of the initial storage capacity. Fortunately, the Tapu reservoir has a sluiceway facility and gorge-shaped reservoir geometry. Therefore, the Tapu reservoir is taken as a study case in this article.

During the flushing operation, a large amount of water is consumed, and normal water supply will be affected afterwards. To satisfy normal water supply with flushing sediment operation, in this study two models including a reservoir simulation model and a sediment-flushing model are established and conjoined to determine operation rule curves with sediment desiltation by flushing operation. The genetic algorithm (GA) is used to optimize the flushing operation rule curves in the reservoir simulation model. Genetic algorithms (GAs) are optimization techniques based on the mechanics of natural selection and natural genetics (Goldberg, 1989). They are efficient, adaptive and robust search processes, producing near-optimal solutions and having a large amount of implicit parallelism. The GAs are now finding widespread applications in business, science and engineering fields. In the field of water resources, the GAs have been applied to a large variety of problems such as groundwater modelling (McKinney and Lin, 1994), pipe network optimization (Simpson et al., 1994), rainfall-runoff model calibration (Wang, 1991) and reservoir operation (Oliveira and Loucks, 1997; Chang and Chang, 2001).

In this article, the concept of the conjunction between the reservoir simulation model and the sedimentflushing model is first illustrated. The reservoir simulation model using the genetic algorithm is presented for the determination of flushing operation rule curves. The development of the sediment-flushing model for calculating of water-surface profile and flushed sediment volume to update the reservoir elevation-storage curve is described. Both established models are then applied to carry out the flushing schedule in the Tapu reservoir for sustainable reservoir operations.

\section{RESERVOIR OPERATION RULE CURVES WITH SEDIMENT FLUSHING}

The reservoir simulation model is based on the continuity of reservoir water to meet the needs of water usage for supply as well as flushing. Owing to sedimentation or flushing sediment, the amount of sediment deposits can be added or subtracted to vary the relationship of reservoir water stage and storage capacity, which should be considered in the reservoir simulation model for long-term operation.

The concept of the model conjunction is illustrated in Figure 1. Based on the operation rule curves obtained by the reservoir simulation model, the amount of flushed sediment volume is calculated by the sedimentflushing model, if the inflow amount of water satisfies the requirement of flushing criteria. The updated elevation-storage curve of the reservoir is then determined for the reservoir simulation model in the next 


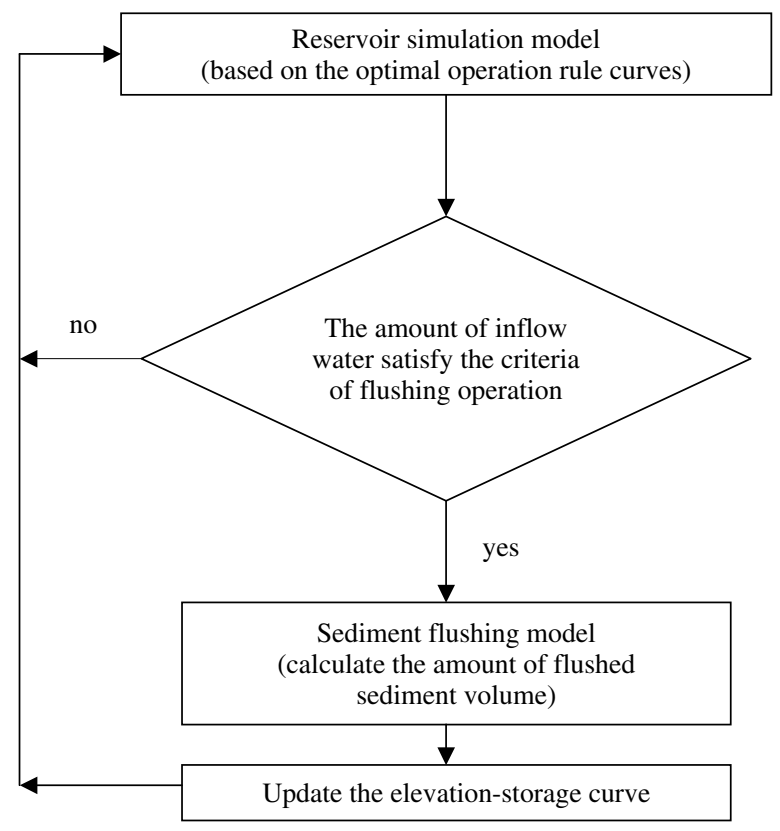

Figure 1. The concept of the reservoir simulation model in conjunction with the sediment flushing model

calculation time interval. Basic theories of the reservoir simulation model and the sediment-flushing model are described in the following sections.

\section{Reservoir simulation model}

To gain operation rule curves with the flushing operation considered, the reservoir simulation model is applied to simulate reservoir operation and optimize the operation rule curves by implementing the genetic algorithm.

The continuity equation is applied in the reservoir simulation model as below

$$
S_{t+1}=S_{t}+\left(I_{t}-O_{t}\right) \Delta T
$$

The simulation interval is considered to be every 10 days; that is, the time interval $\Delta T$ equals to 10 days. Variable $S_{t+1}$ is the accumulative amount of the storage over the next 10-day period, $S_{t}$ is the accumulative amount of the storage over the present 10-day period and $O_{t}$ is the accumulative amount of the outflow in the interval of the 10-day period. The historical sequential 10-day inflow is used as the input of the reservoir simulation model, and the operating pattern must follow the operation rule curves set by the regulation of the reservoir operation. The operation rule curves include the upper limit curve and the lower limit curve. Based on the operation rule curves, the operation policy is regulated.

\section{Optimizing the operation rule curves by genetic algorithm}

The model is evaluated based on a long-term stream flow records. The computing time is quite long for each run; consequently it is impossible to run the model for all the possible cases in its feasible domain. The GA provides a feasible way to conquer a complex system with so many parameters (i.e. inflection points) to be adjusted. The operation rule curves can be imaged as inflection points (i.e. parameters). The coordinates of the parameters are unknowns. The procedures of the GA are described as follows. 
1. Coding the parameter set strings. The GA requires encoding schemes that transform the vector of variables to a structure that permits genetic operations. There are two curves and each curve has 36 inflection points (in the 10-day period) so that the total inflection points are 72 . Using the described encoding scheme, the problem may be defined by a set of 72 parameters (the coordinate values of the inflection points)(Chang and Chen, 1998). One set of constraints requires that the simultaneous coordinate values of upper limit points are greater than the lower limit point, and all the values must be within the boundaries of the minimum admissible storage level and the maximum allowable storage level.

2. Establishing the objective function. The shortage index (SI) proposed by the US Army Corps of Engineers (Hydrologic Engineering Center, 1966, 1975) could represent the lumped water supply shortage and reflect the severity of the water shortage; consequently, it is used as the objective function for this study. The SI is defined as (Hsu, 1995)

$$
S I=\frac{100}{N} \sum_{i}\left(\frac{\text { water deficit in the period } i}{\text { water supply demand in the period } i}\right)^{2}
$$

where $N$ is the total number of periods and $\Sigma$ represents the summation of the indicated values for all the periods. The continuous equations have been set and two objects must be satisfied, required water supply and water for flushing operation.

The procedure of this model includes two modules: the reservoir simulation module and optimization module. The reservoir simulation module computes the shortage index (SI) when the model inputs new operational rule curves that the optimization module produce. The optimization module searches new operation rule curves according to the shortage index (SI) that the reservoir simulation module computes. Shortage index (SI) is considered as a fitness function. The combination of these two parts to search the best set of operation rule curves is a crucial task.

3. Setting the GA's parameters. Values of the GA's parameters must be defined before the algorithm is used. These parameters include the sample-size population and the probabilities of cross-over and mutation. Although determining the best values of parameters is important and several studies have attempted this (Grefenstette, 1986; Schaffer et al., 1989), no uniform rule has been found yet. In this circumstance, trialand-error procedures are used to find a good set of the parameter values. The suggested set of parameter values that consistently led to good results in this study is shown in the following: population size $=50$, cross-over probability $=0.9$ and mutation rate $=0.01$ (Goldberg, 1985). For the binary coded GA, the string length of each variable is set as 4 .

4. Combining the GA module with reservoir simulation module. After the genetic algorithm module is established, the optimization module, GA, generates a set of operation rule curves parameters, of 72 points. Then the reservoir simulation module simulates the results of operation by using these operation rule curve parameters and calculates the objective function value, i.e. SI. The circular procedure is repeated for the designed population size. After the production, crossover and mutation (Grefenstette, 1986) are performed, the procedure is propagated to the next generation, unless the system performance becomes stable (Figure 2). The best operation rule curves are sought using the combination of two modules: reservoir simulation module and genetic algorithm module.

\section{SEDIMENT FLUSHING MODEL}

During the flushing operation, estimating the amount of sediment removed from the reservoir is important in order to calculate reservoir storage changes and update the reservoir storage. The sediment-flushing model is devised to calculate the amount of flushed sediment volume in each flushing event for long-term simulation. 


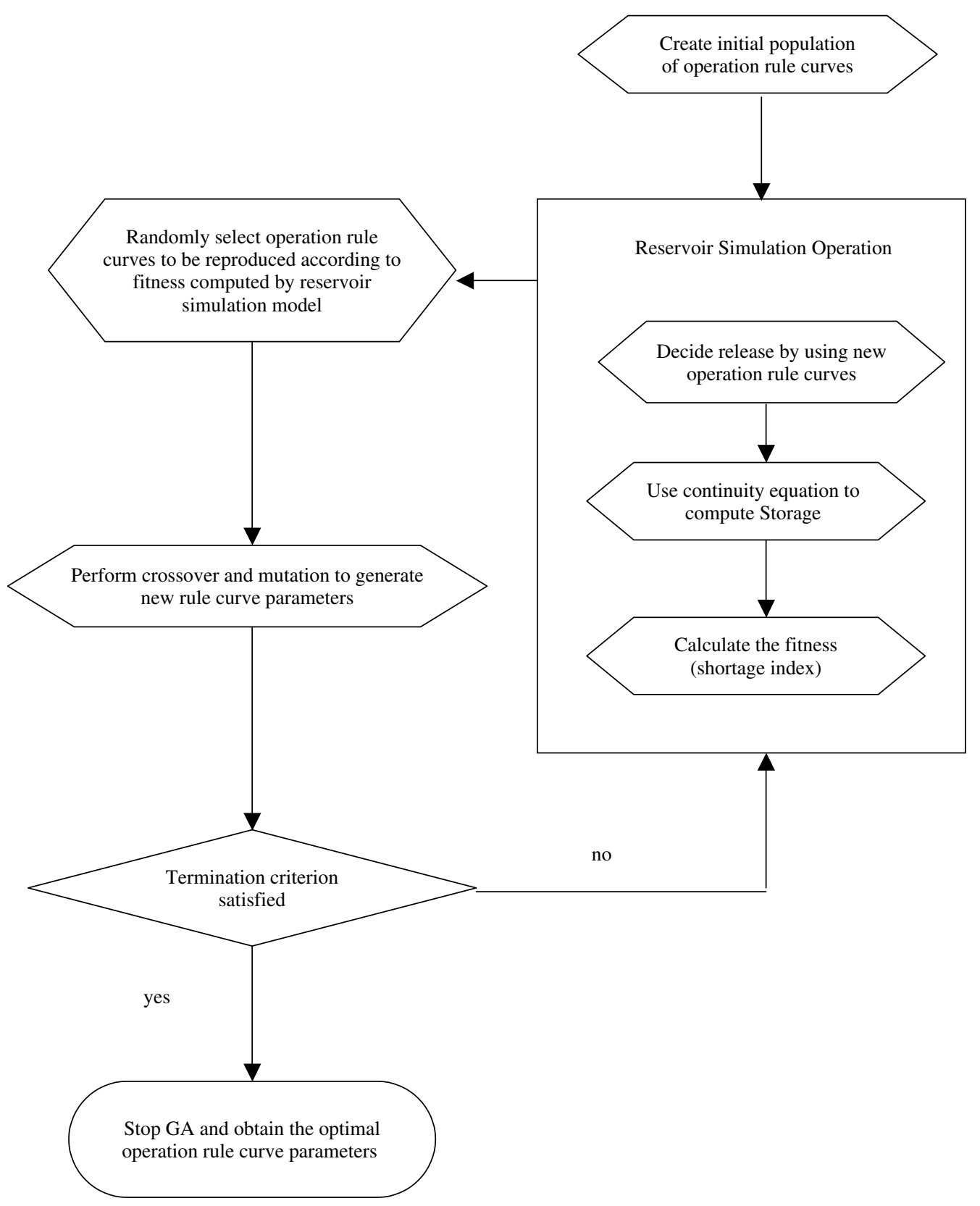

Figure 2. The procedures of optimizing reservoir operation rule curves by the genetic algorithm

For this the reason, the sediment-flushing model, which is coupled with the reservoir simulation model, should not be complicated or too detailed with regard to the mechanism of water-sediment dynamics.

In the following section, the basic theory of the calculation of flushed sediment volume is described. Information of the hydraulic parameters, such as the water-surface profile of the reservoir, also is needed. A simple one-dimensional mathematical model developed to calculate the bed-elevation and water-surface profiles along the reservoir is presented and described herein. 


\section{Estimate flushed sediment volume}

Considering drawdown flushing, the sediment transport rate has been investigated by several researchers (Lai and Shen, 1995; Chien and Wan, 1999), and it can be a function of the outflow discharge $\left(Q_{0}\right)$, energy slope $(S)$, flushing channel width, sediment size, etc. The sediment Research Laboratory (SRL, 1979) proposed a formula for the outflow sediment discharge during drawdown flushing, and the assumptions are: (i) the flow is locally uniform (i.e. $S=S_{\mathrm{w}}=S_{0}$, where $S_{\mathrm{w}}$ is the water-surface slope and $S_{0}$ is the bed slope) in the flushing processes and the Manning formula can be applied; (ii) the total load transport equation is used by applying the Wuhan transport equation, which is related to the parameter $u^{3} / g h w$, in which $u$ is the average channel velocity, $g$ is the gravitational acceleration, $h$ is the channel flow depth and $w$ is the sediment particle falling velocity. Considering the above assumptions, the sediment outflow discharge is expressed as

$$
Q_{\mathrm{os}}=E \frac{Q_{0}^{1 \cdot 6} S^{1 \cdot 2}}{B^{0 \cdot 6}}
$$

The flushing coefficient $E$ represents the erodibility of deposits and it can be related to the sediment size and depositional environments. The above equation was examined with both the laboratory data (Lai and Shen, 1996) and by the field data collected from several reservoirs in China (SRL, 1979). From the relationship in Equation (3), the lower the $E$ value, the stronger the flow resistance. The amount of flushed sediment volume $\left(V_{\mathrm{os}}\right)$ then can be calculated by

$$
V_{\mathrm{os}}=\int_{\mathrm{o}}^{T} Q_{\mathrm{os}} \mathrm{d} t
$$

where $T$ is the duration of the flushing operation.

\section{Calculating the water surface profile}

For calculating the outflow sediment discharge, the water-surface slope in reservoir can be obtained from the water-surface profile calculation. A one-dimensional energy equation is applied and solved by using the standard step method to calculate hydraulic parameters such as velocity, depth and water-surface elevation at each cross-section for every successive discharge. The energy equation is written as follows (Hydrologic Engineering Center, 1993)

$$
W_{2}+\frac{u_{2}^{2}}{2 g}=W_{1}+\frac{u_{1}^{2}}{2 g}+h_{\mathrm{f}}
$$

where $W_{1}$ and $W_{2}$ are the average water stages at the ends of the reach, respectively, $u_{1}$ and $u_{2}$ are the average velocity at ends of the reach, respectively, $h_{\mathrm{f}}$ is the energy loss calculated by the Manning equation and $g$ is the acceleration of gravity.

In the process of drawdown flushing, the bed elevations along the flushing channel will vary with the processes of erosion and deposition. It can be described by the sediment continuity equation as

$$
\frac{\partial G}{\partial x}+B(1-\lambda) \frac{\partial Z}{\partial t}=0
$$

where $G$ is the sediment load at the upstream and downstream cross-sections, $x$ is the distance along the channel, $B$ is the width of the flushing channel, $\lambda$ is the porosity of bed material and $Z$ is bed elevation. The above equation can be written in finite difference form for a certain section at point $P$ in equation (7)

$$
\frac{G_{\mathrm{u}}-G_{\mathrm{d}}}{\left(L_{\mathrm{d}}+L_{\mathrm{u}}\right) / 2}+\frac{B_{p}(1-\lambda)\left(Z_{p}^{\prime}-Z_{p}\right)}{\Delta t}=0
$$

In the computational region, sediment load $G_{\mathrm{u}}$ at the upstream end and $G_{\mathrm{d}}$ at the downstream end can be calculated by using Equation (3); $L_{\mathrm{u}}$ and $L_{\mathrm{d}}$ are the upstream and downstream reach lengths, respectively; 
$B_{P}$ is the width of the flushing channel at point $P ; Z_{p}$ is initial elevation of bed material surface at point $P ; Z_{p}^{\prime}$ denotes the bed elevation for next time-step; and $\Delta t$ is the computational time-step. Equation (7) can be applied to simulate the channel bed variation at each cross section in the sediment-flushing model. The variables used are shown in Figure 3. The bed elevation at point $P$ for next time-step is expressed as

$$
Z_{p}^{\prime}=Z_{p}-\frac{2 \Delta t}{(1-\lambda) B_{p}} \frac{G_{\mathrm{u}}-G_{\mathrm{d}}}{L_{\mathrm{d}}+L_{\mathrm{u}}}
$$

\section{APPLICATION TO THE TAPU RESERVOIR}

Flushing sediment though a reservoir has been applied successfully and found to be effective in many places around the world (Morris and Fan, 1998; Shen and Lai, 1996). Few reservoirs in Taiwan have conducted desilting operations by flushing because of the absence of a sediment sluiceway facility at most of the reservoirs. The removal of sediment by means of dredging or excavation is generally expensive, but it is frequently used owing to the strong demand for water supply in Taiwan. In this study, the established models are applied to the Tapu reservoir, which has faced serious sedimentation problems since the dam was completed. Fortunately, it has sluiceway facilities and a gorge-shaped reservoir geometry, which means that it has the potential to flush sediment through.

\section{Description of the Tapu reservoir}

The Tapu reservoir is formed by the Tapu dam located on the middle reach of the Aumei River and about $6 \mathrm{~km}$ from the junction with the Chungkung River, which flows westward to the Taiwan Strait. The location and its watershed area are shown in Figure 4a. It has a natural drainage area of $100 \mathrm{~km}^{2}$. The Tapu dam, completed in 1960 , is a 20.9 -m-high and 98.9 -m-long concrete gravity dam with four spillways (with a $8 \cdot 3$ $\mathrm{m}$-high and 8-m-wide gate each) and one sluiceway (with a 3.8- m-high, 8-m-wide gate) controlled by tank gates. The crest of the sluiceway is $6.3 \mathrm{~m}$ lower than that of the spillway. The design capacity of the four spillways is $1.937 \mathrm{~m}^{3} / \mathrm{s}$, and of the sluiceway is $440 \mathrm{~m}^{3} / \mathrm{s}$. With a maximum level of $69.6 \mathrm{~m}$, the reservoir impounds a lake about $8 \mathrm{~km}$ in length and forms a water surface area of 135 ha. The initial storage capacity

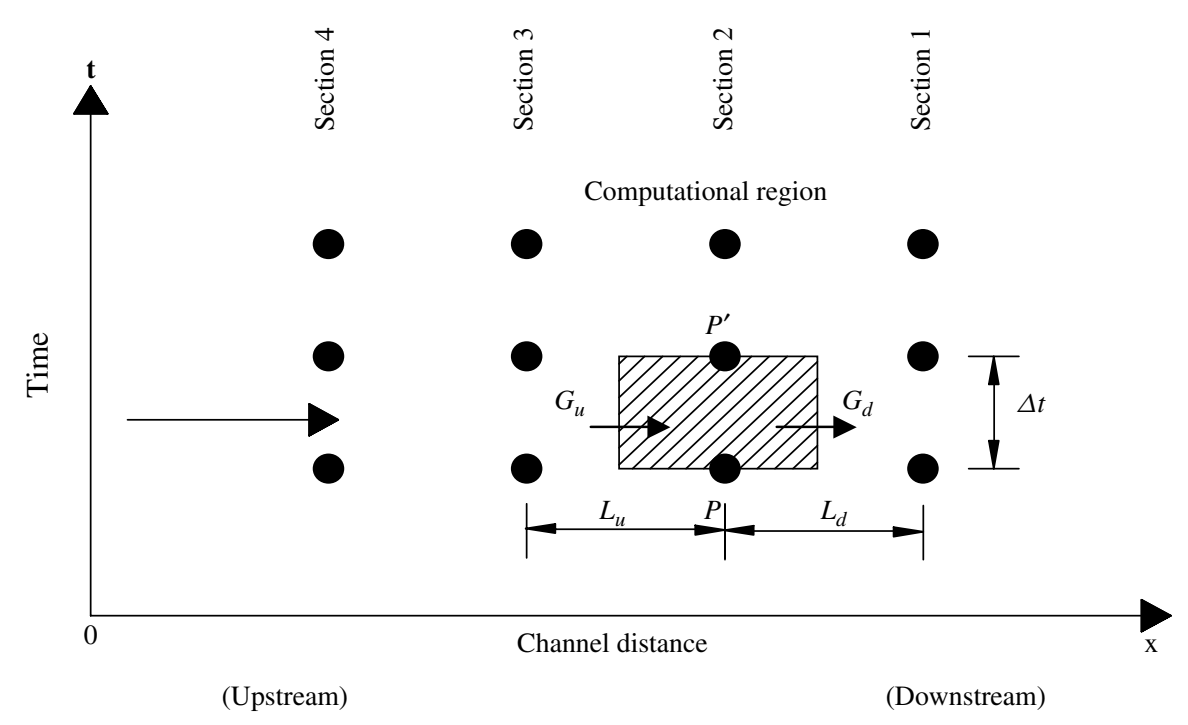

Figure 3. Computational grid in time and flow direction $(x)$ 
(a)

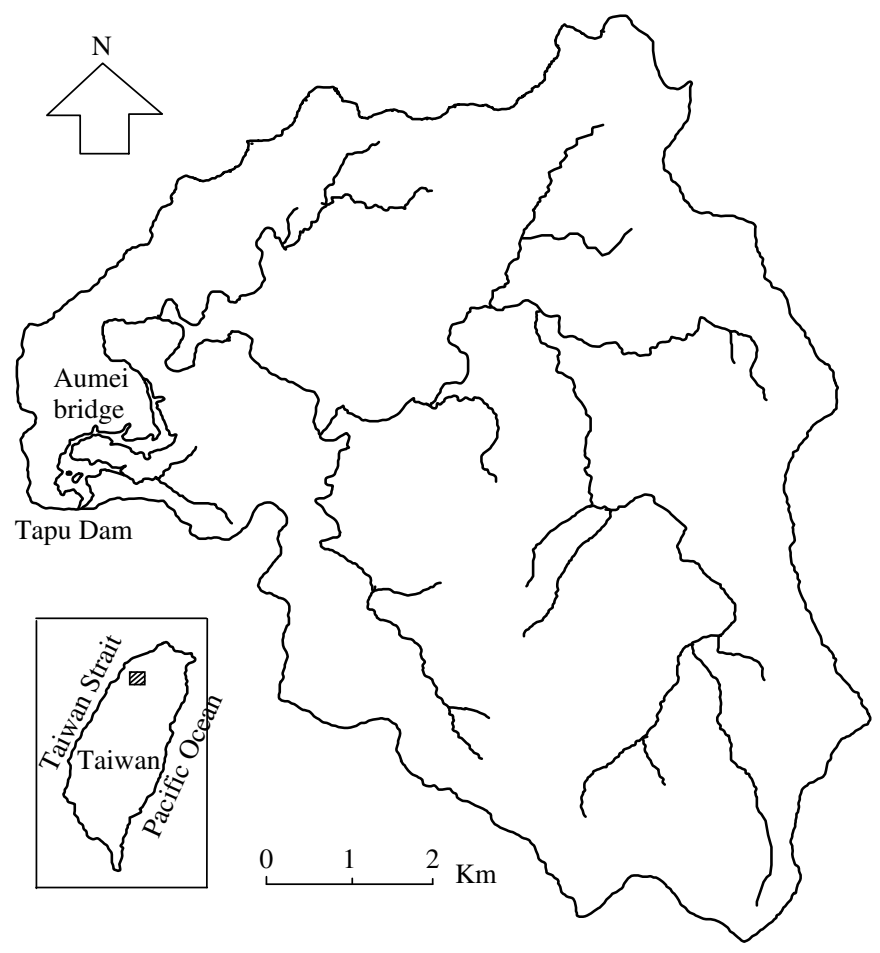

(b)

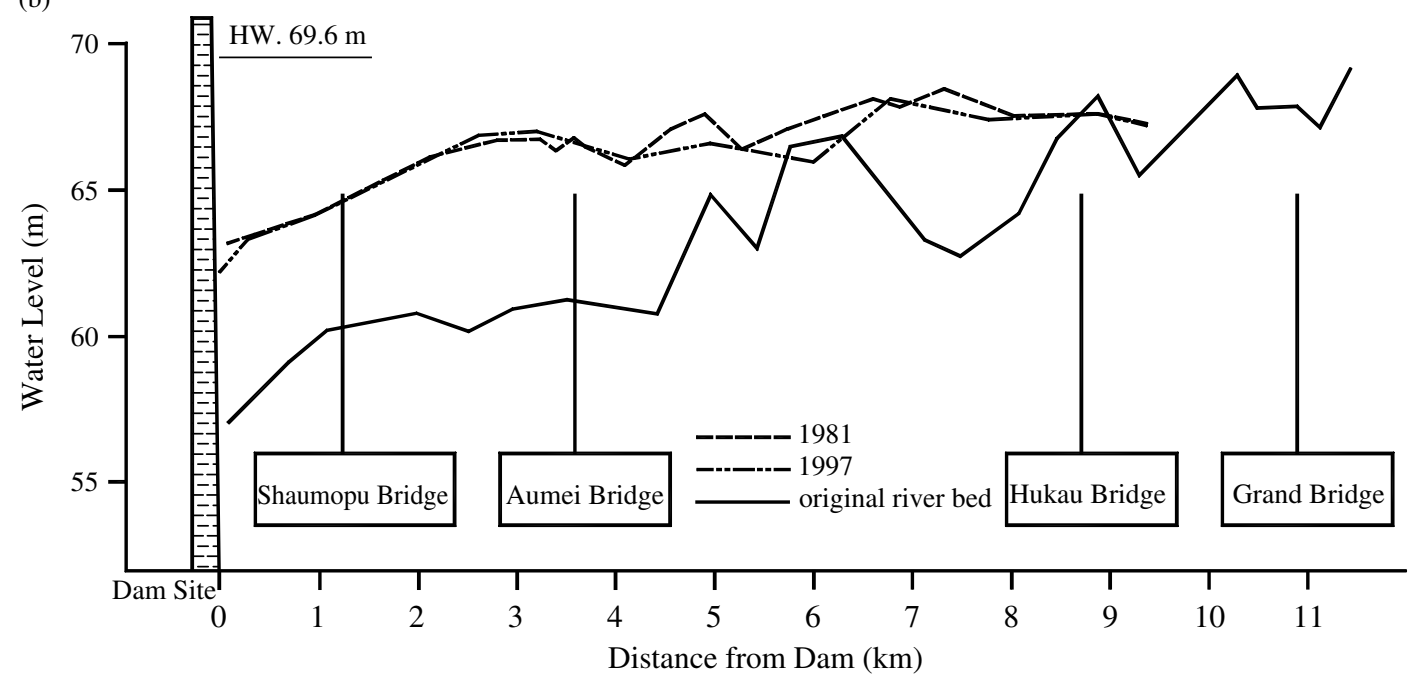

Figure 4. (a) Location of Tapu reservoir. (b) Longitudinal bed profile variations along Tapu reservoir

was $9.26 \times 10^{6} \mathrm{~m}^{3}$, and its initial active storage was $7.96 \times 10^{6} \mathrm{~m}^{3}$. The geometry of the Tapu reservoir is of a gorge shape.

The mean annual inflow is $1.76 \times 10^{8} \mathrm{~m}^{3}$. Accordingly, the Tapu reservoir has a relatively small hydrological size because the ratio of the storage (surveyed in 1997) to the mean annual inflow is 0.031 (i.e. $5.5 \times 10^{6} \mathrm{~m}^{3} / 1.76 \times 10^{8} \mathrm{~m}^{3}$ ). This indicates that the Tapu reservoir has the potential to be refilled 
Table I. Annual 10-day average inflow and water demand in the Tapu reservoir

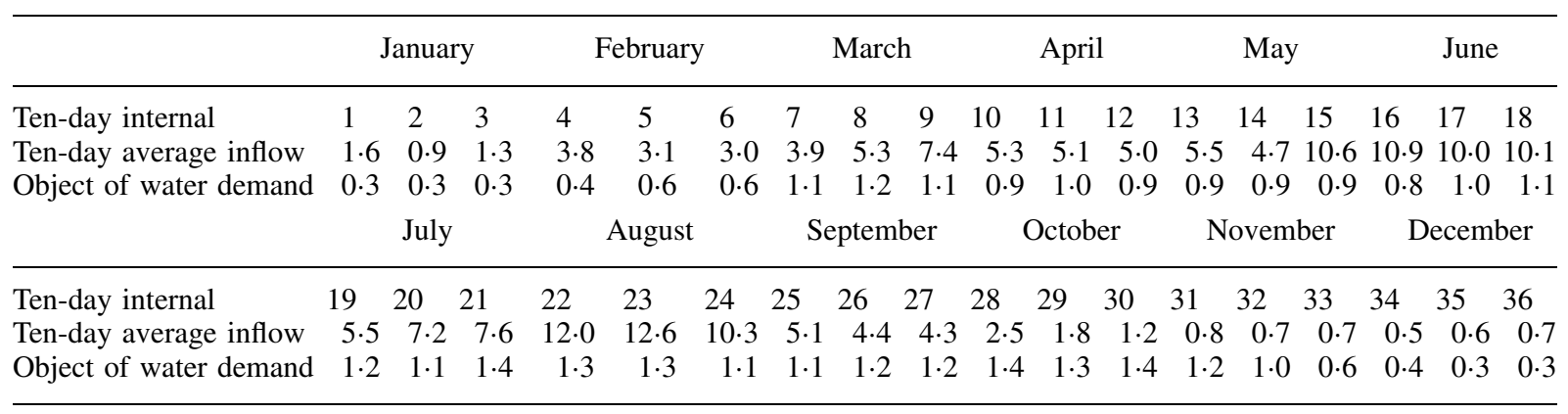

quickly after the flushing operation is finished. The wet season usually occurs between April and September in the watershed of the Tapu reservoir. Based on the data from 1961 to 1996, the 10-day average inflow discharges are listed in Table I. For the regulation of water supply in the Tapu reservoir, the object of water demand based on a 10-day average period is also listed in Table I. The reservoir release policy is determined by the water stage according to particular limit curves, which are described as follows.

1. If the water level is above the upper limit curve, water release should be increased to keep the water level at the upper limit.

2. If the water level is between the upper and lower limit curve, water release must be cut back by $20 \%$.

3. If the water level is below lower limit curve, water release must be cut back by $30 \%$.

Owing to intensive mining activities in the watershed and lack of proper measures for reservoir desiltation, the storage capacity of the Tapu reservoir decreased very rapidly during the period of 1960 to 1970 . The Tapu reservoir has accumulated a significant amount of sediment since dam completion. Sediment-laden flow from upstream entering the reservoir mainly happens in storm events or typhoons. According to a reservoir bed elevation survey in 1987, cumulative deposits once filled up 51\% of the initial storage capacity. Serious sedimentation has raised the flood stage along the tail reach of the reservoir, threatened the safety of local people, and forced the government to build levees for protection. The depositional pattern has become wedgeshaped since 1981, and the longitudinal bed profile along the main channel reservoir is plotted in Figure $4 \mathrm{~b}$. From the historical records of water levels at the Tapu dam, we found that water stage had been kept relatively high for water demand by obeying the original operation rule curves as shown in Figure 5. Consequently, incoming sediment particles have settled down rapidly along the reservoir since the dam was completed. Although the operators carried out a set of flushing operation rule curves to consider flushing sediment by

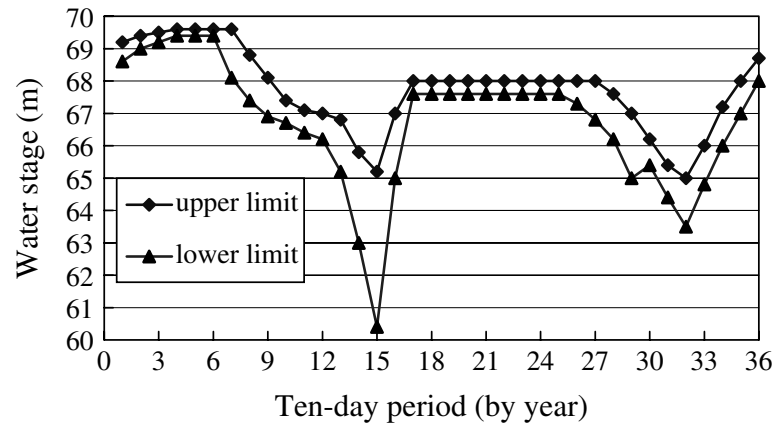

Figure 5. Original operation rule curves of Tapu reservoir 


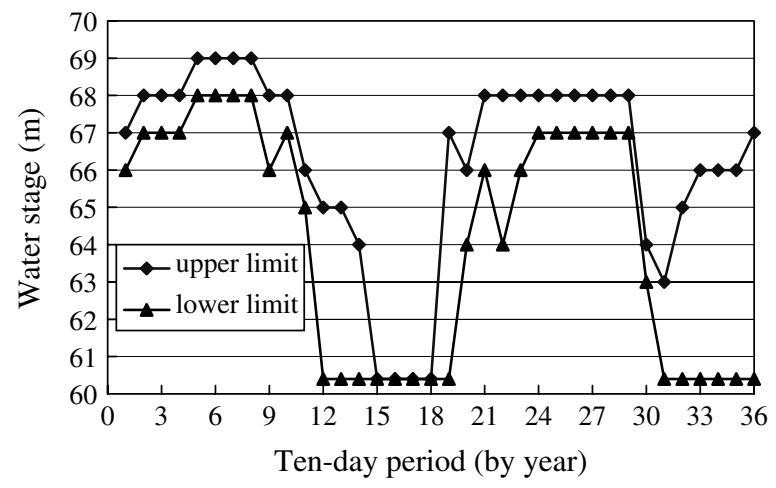

Figure 6. Original flushing operation rule curves of Tapu reservoir

using conventional methods, this set, called original flushing operation rule curves as presented in Figure 6, has never been used in the Tapu reservoir.

To deal with sedimentation problems, the manager of the Tapu reservoir has tried to practice flushing. Since 1991, by operating the sluiceway, several drawdown flushing operations have been attempted by emptying the reservoir. Based on the sedimentation survey data, it is found that a significant amount of deposits have been removed during flushing in storms or typhoons.

\section{Estimation of flushed sediment volume}

Based on the data of water stages at the dam from 1991 to 1996, there have been about 10 full drawdown flushing operations by emptying the reservoir. Owing to the wedge-shaped depositional pattern in the Tapu reservoir, the effectiveness of drawdown flushing was significant, especially within a range of $1.5 \mathrm{~km}$ from the dam axis (Chang and Lai, 1999). According to the records, six of them were conducted in the monsoon season (during May to June in Taiwan), and three of them during typhoons. For instance, the data obtained by the automatic recording system of water stage and outflow water discharge at the dam are plotted in Figures 7a and 8a for the flushing events on 11 June 1997 and 31 July 1996 (Typhoon Herb), respectively. In Figure 7a, the outflow water discharge hydrograph is a single peak flood, and water stages drop from high water level to a relatively low level, which can generate significant water-surface slopes to increase the outflow sediment discharge. Another pattern for a typhoon event is a multipeak flood with longer duration, as shown in Figure 8a for Typhoon Herb.

Determination of flushing coefficient $E$. Based on sedimentation survey records, there were no bed elevation data measured before and after flushing events, except the data for Typhoon Herb. Therefore, useful data from the flushing event operated during Herb Typhoon are used to calibrate the flushing coefficient $E$ and then calculate the amount of flushed sediment volume using equation (4). For the flushing operation during Typhoon Herb, it is found by sedimentation survey that the reservoir storage increased $140000 \mathrm{~m}^{3}$ in volume from 1996 to 1997. In contrast, the trend of storage capacity has decreased linearly from 1971 to 1987 . Without desilting operations, the yearly storage capacity loss as a result of annual deposition in the period 1971 through to 1987 is estimated to be $44500 \mathrm{~m}^{3} /$ year. Assume that incoming sediment yield at the upstream boundary (Aumei bridge) is about the storage capacity loss per year. By considering the increased volume of storage capacity after flushing operations during Typhoon Herb and the annual deposition rate of the Tapu reservoir, the flushed sediment volume during this typhoon can be estimated to be $184500 \mathrm{~m}^{3}$.

For water-surface profile calculation, geometry data of six cross-sections located at $0 \mathrm{~m}$ (downstream boundary at dam), $900 \mathrm{~m}, 1200 \mathrm{~m}, 2200 \mathrm{~m}, 2800 \mathrm{~m}$ and $3800 \mathrm{~m}$ (upstream boundary at Aumei bridge) away from dam along the Tapu reservoir are input in the sediment-flushing model. From field observation, the 

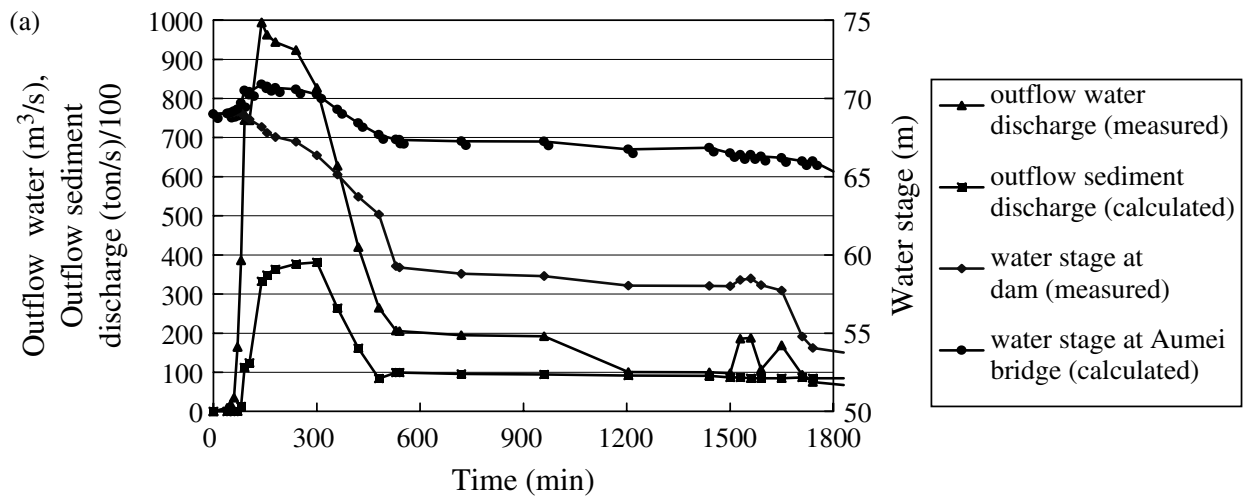

(b)

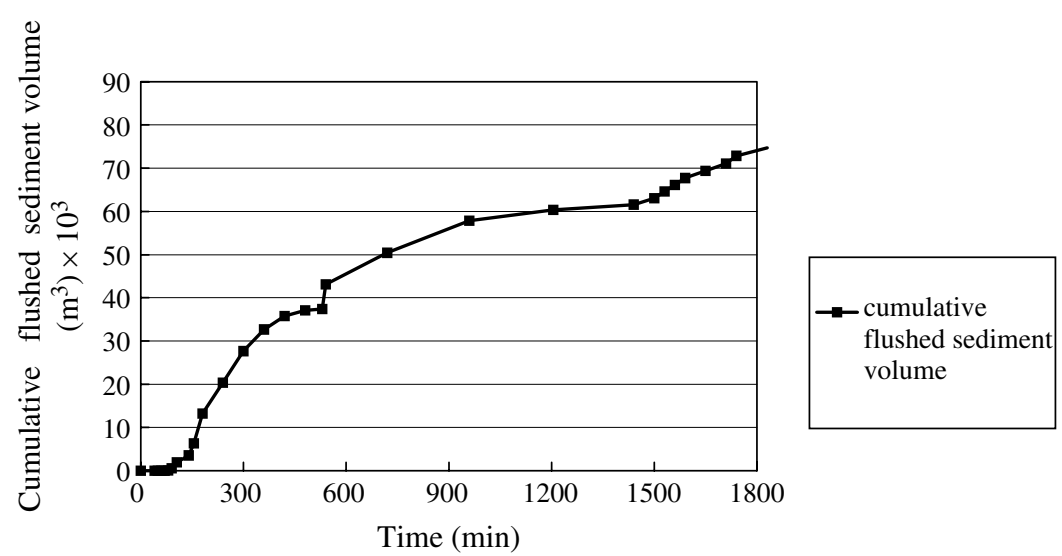

Figure 7. (a) Outflow water/sediment and water stage against time on June 11 1997. (b) Cumulative flushed sediment volume on June 11 1997

flushing channel width is set to be the main channel width, which is about $50 \mathrm{~m}$ in the calculation domain. The calculation time-step is $5 \mathrm{~min}$.

Assume that the flow condition is quasi-steady in the reservoir during the flushing operation at the time of Typhoon Herb. An outflow water discharge hydrograph and water stage variations against time at the dam are included in order to calculate the water-surface profile along the reservoir by using Equation (5). In addition, using Equation (8), one can estimate the bed elevation changes during flushing. As the average water-surface slope can be calculated by the water-surface difference over the distance from the dam to the Aumei bridge, the total amount of flushed sediment volume is approximated to be $185000 \mathrm{~m}^{3}$ by trial-and-error using different values of flushing coefficient $E$. It is found that the flushing coefficient is calibrated to be 3.3 for best fitting to the total amount of flushed sediment volume calculated using Equation (4). The calculated water stage at the Aumei bridge and outflow sediment discharge at the dam with respect to time are presented in Figure 8a.

Calculation of flushed sediment volume. According to calibrated $E$, the data for outflow water discharge and water stage at the dam in the flushing event on 11 June 1997 are applied to calculate water-surface slope and then outflow sediment discharge. The simulated results against time are plotted in Figures 7a and 8a. Using Equation (4), the cumulative flushed sediment volume is obtained by adding up the outflow sediment discharge as time increases. Figures $7 \mathrm{~b}$ and $8 \mathrm{~b}$ show cumulative flushed sediment volume varying with time for these two events, respectively. The cumulative flushed sediment volume in the flushing event is far less 


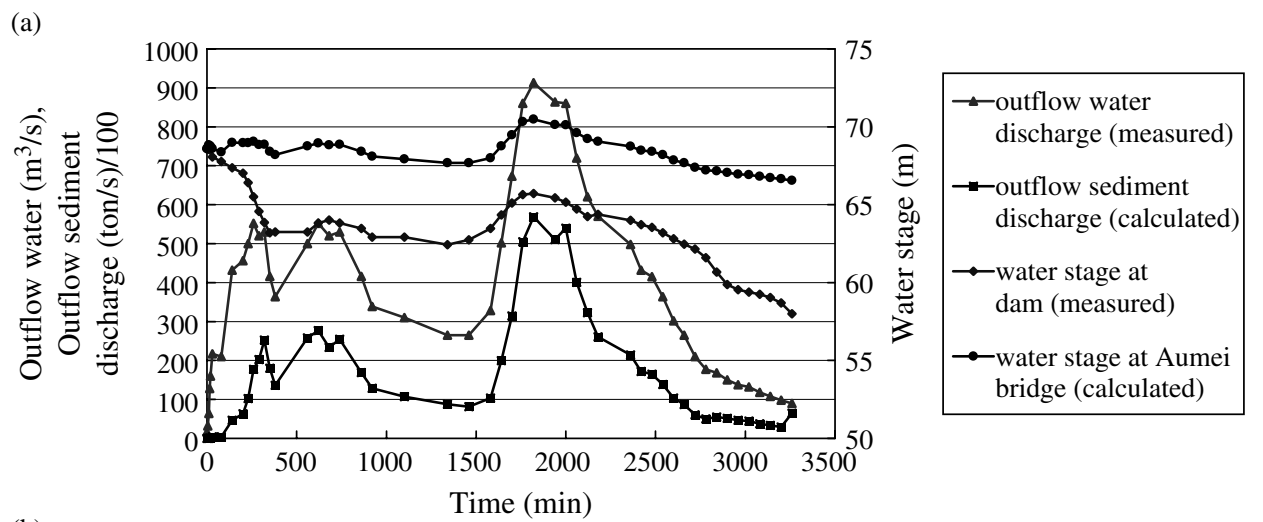

(b)

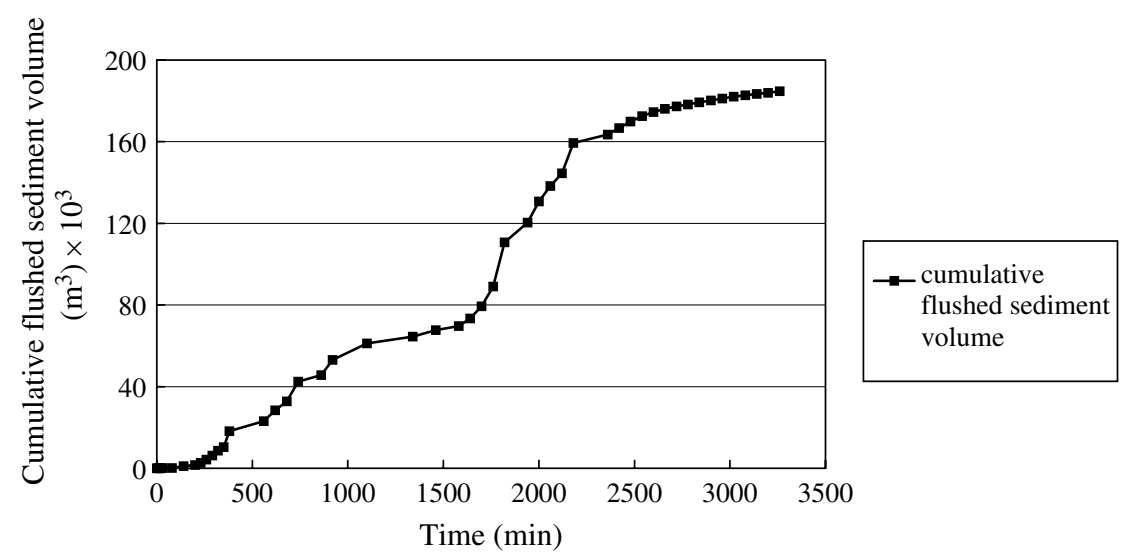

Figure 8. (a) Outflow water/sediment and water stage against time during Typhoon Herb. (b) Cumulative flushed sediment volume during Typhoon Herb

than that in the typhoon because the flood with multipeak discharges in this event is larger, and the duration (about 2.4 days) of flushing operation is also longer.

\section{Operation rule curves for flushing operation}

To deal with water supply and flushing operation of the Tapu reservoir, the reservoir simulation model adopts the genetic algorithm to optimize operation rule curves. Historical sequential records from 1961 to 1996 are used as a series of input of the model. According to yearly 10-day average inflow discharge in Table I, the wet season of the year is from April to September. Therefore, this study presumes two conditions suitable for the flushing operation proceed in order to establish two new sets of flushing operation rule curves, $\mathrm{F} 1$ and F2. One condition is that if the inflow of the reservoir is greater than $7.5 \times 10^{6} \mathrm{~m}^{3}$ (about one and a half times the present storage capacity) in May, then the flushing operation begins. The other condition is that if the inflow of the reservoir is greater than $15 \times 10^{6} \mathrm{~m}^{3}$ (about three times the present storage capacity) in May, the flushing operation begins. Corresponding to the object of water demand listed monthly in Table I, the reservoir simulation model with the genetic algorithm is to search for the optimal operation rule curves under the above conditions. These two sets of flushing operation rule curves, F1 and F2, are obtained and shown in Figure 9a and b, respectively. At the same time, the original reservoir operation rule curves (see Figure 5) and the original flushing operation rule curves (see Figure 6) also are used for simulation. The comparisons of simulated results are listed in Tables II(a and b) for days of water deficit, shortage index (SI), outflow rate, water deficit rate, etc. From Tables II(a and b), it is concluded that the operation rule curves 
(a)

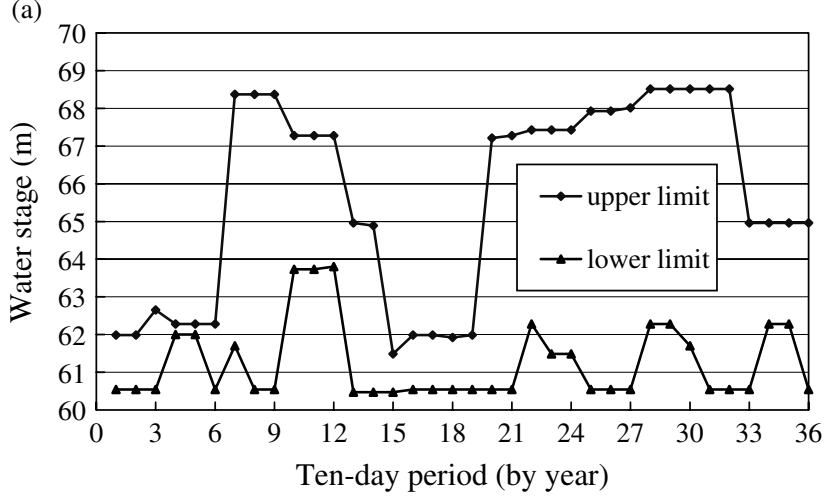

(b)

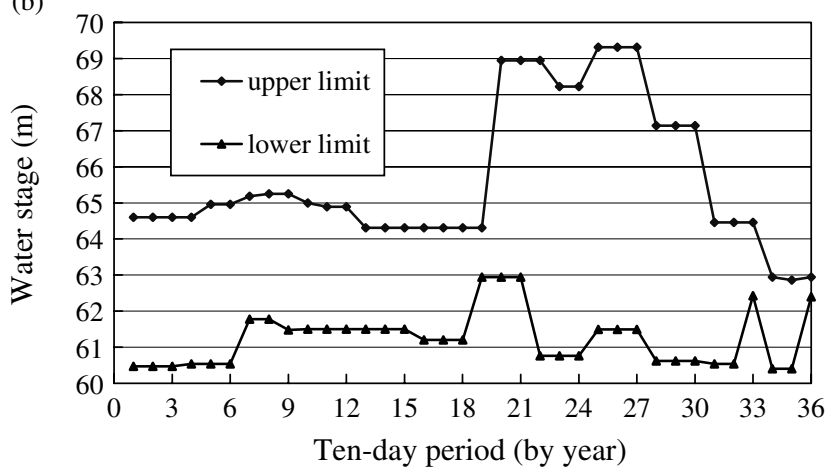

Figure 9. (a) Flushing operation rule curves F1 obtained by genetic algorithm. (b) Flushing operation rule curves F2 obtained by genetic algorithm

Table II(A). Simulated results by consuming $7.5 \times 10^{6} \mathrm{~m}^{3}$ water for flushing

\begin{tabular}{lcccccc}
\hline & A & B & C & $\begin{array}{c}\text { Shortage } \\
\text { index (SI) }\end{array}$ & $\begin{array}{r}\text { Overflow } \\
\text { rate }^{\mathrm{a}}(\%)\end{array}$ & $\begin{array}{c}\text { Water deficit } \\
\text { rate }^{\mathrm{b}}(\%)\end{array}$ \\
\hline Original operation rule curves & 1039 & 81 & 176 & 1.66 & $77 \cdot 6$ & $3 \cdot 1$ \\
Original flushing operation rule curves & 1140 & 53 & 117 & 1.13 & 77.5 & $2 \cdot 7$ \\
F1 & 1183 & 88 & 25 & 0.75 & 77.5 & $2 \cdot 6$ \\
\hline
\end{tabular}

Table II(B). Simulated results by consuming $15 \times 10^{6} \mathrm{~m}^{3}$ water for flushing

\begin{tabular}{lrrrrrr}
\hline & A & B & C & $\begin{array}{c}\text { Shortage } \\
\text { index (SI) }\end{array}$ & $\begin{array}{c}\text { Overflow } \\
\text { rate }^{\mathrm{a}}(\%)\end{array}$ & $\begin{array}{c}\text { Water deficit } \\
\text { rate }^{\mathrm{b}}(\%)\end{array}$ \\
\hline Original operation rule curves & 996 & 84 & 216 & 2.00 & 74.4 & 6.4 \\
Original flushing operation rule curves & 1099 & 62 & 147 & 1.42 & 74.3 & $6 \cdot 1$ \\
F2 & 1187 & 70 & 39 & 1.00 & 74.0 & $5 \cdot 0$ \\
\hline
\end{tabular}

A, the number of days when water stage is above upper limit in 10-day period.

$\mathrm{B}$, the number of days when water stage is between upper limit and lower limit in 10-day period.

$\mathrm{C}$, the number of days when water stage is below lower limit in 10-day period.

${ }^{\text {a }}$ Outflow rate: accumulative amount of water outflow/accumulative amount of water inflow.

${ }^{b}$ Water deficit rate: accumulative amount of water deficit/ accumulative amount of water requirement. 
produced by the genetic algorithm present better performance in terms of lower SI and water deficit rate; that is, the genetic algorithm is apparently better than the traditional search method for optimizing the operating rule curves.

Flushing operation by yearly base. The flushing operation rule curves are basically to satisfy the object of water demand (see Table I) and water usage consumed in the flushing operation. In the previous section, two new sets of flushing operation rule curves were obtained by assuming a different amount of water usage for flushing in May. To examine how satisfactory four sets of operation rule curves are, including the original operation rule curve, the original flushing operation rule curves and flushing operation rule curves F1 and $\mathrm{F} 2$, the reservoir simulation model is applied by increasing water usage to $7.5 \times 10^{6}$ or $9 \times 10^{6} \mathrm{~m}^{3}$ in each specified month for 36 years, by using the historical sequential data from 1961 to 1996. The results of the simulation shown in Figure 10b reveal that the flushing operation rule curves F2 have the lowest values of water deficit rate in each month. The best timing for the flushing operation during the year is May or June. In addition, according to the inflow data of 10-day average discharge in Table I, there is plentiful inflow to refill the reservoir, both for flushing and for water supply demand after May or June. Flushing in May or June can reduce the risk of refilling the reservoir in the forthcoming period, while the reservoir has been drained during the draw down water stage in the flushing operation.

\section{Scheduling of flushing operation}

To schedule the flushing operation in the Tapu reservoir, the sediment-flushing model is combined with the reservoir simulation model to meet the object of water usage with flushing operation. In the previous section
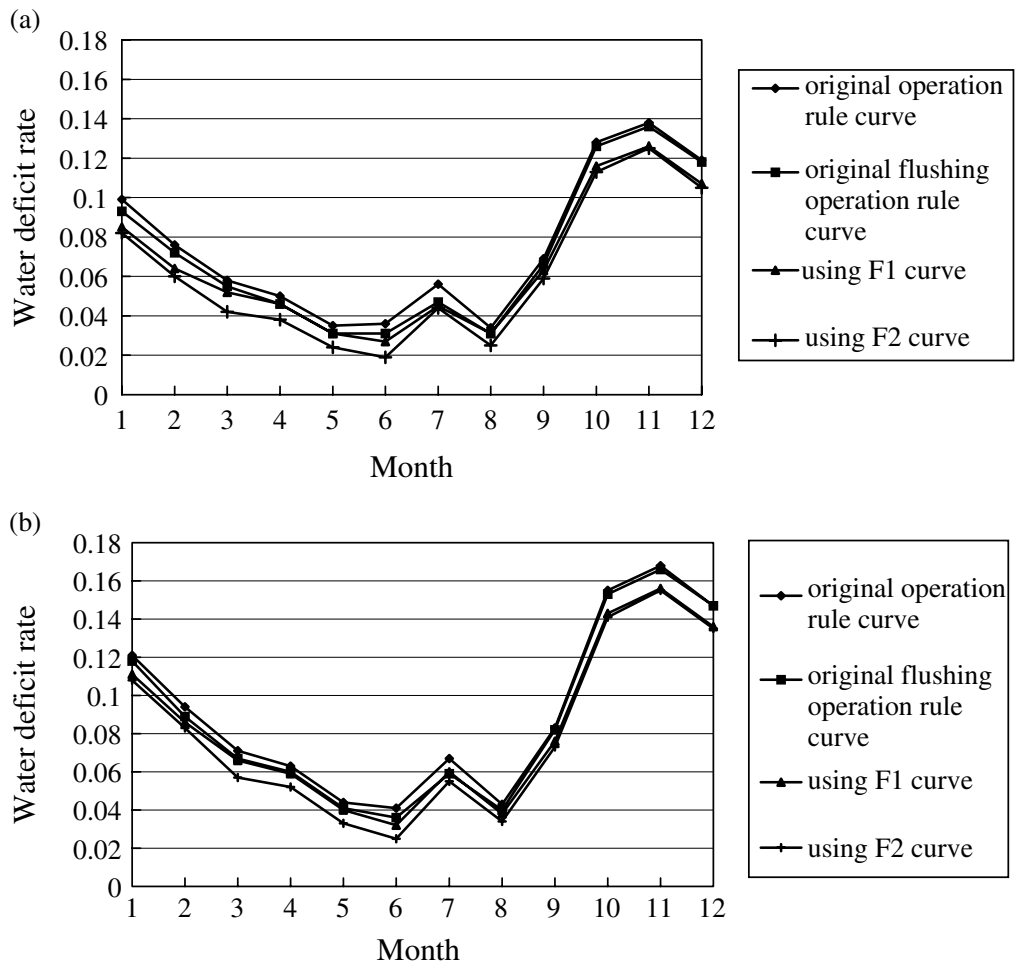

Figure 10. (a) Simulated results of water deficit in each month by increasing water supply to $7 \cdot 5 \times 10^{6} \mathrm{~m}^{3}$. (b) Simulated results of water deficit in each month by increasing water supply to $9 \times 10^{6} \mathrm{~m}^{3}$ water supply 
the genetic algorithm was adopted to optimize the new set of flushing operation rule curves F2 for the Tapu reservoir, as shown in Figure 9b. Accordingly, the best timing for flushing should be set in May or June on a yearly basis.

Practicing flushing in the Tapu reservoir to coincide with wet seasons allows sufficient inflows to be gained and increases the chances to refill the reservoir after flushing. As presented in Figure 7a, the total amount of water used for this flushing operation (on 11 June 1997) was estimated to be $30 \times 10^{6} \mathrm{~m}^{3}$. From observation, there was not much sediment deposition at the downstream river after the gates closed. According to Lai and Shen (1996), flushing efficiency ( $\mathrm{FE}=$ flushed sediment/water usage in volume) drops rapidly when reservoir water-surface slope and outflow water discharge decrease significantly. Therefore, reservoir operators could close all gates $8 \mathrm{~h}$ after the flushing operation begins. In this way, the amount of water consumed would be reduced to $18 \times 10^{6} \mathrm{~m}^{3}$.

From field observation using photographs and videofilm, the flushing operation on 11 June 1997 was a typical and successful practice to flush a significant amount sediment though the Tapu reservoir, especially within the simulation reach between the dam and Aumei bridge. Therefore, hydrographic patterns of outflow water discharge and water stage at the dam in this flushing event are adopted as typical patterns in the present study. As mentioned previously, the entire volume of water used in flushing was about $30 \times 10^{6} \mathrm{~m}^{3}$ for the event of 11 June 1997. If a more effective operational procedure is desired to excavate a significant amount of sediment but consume less water, the gates may be closed about $8 \mathrm{~h}$ after flushing begins, and the amount of water needed is about $18 \times 10^{6} \mathrm{~m}^{3}$. This can save about $40 \%$ of the water usage; however, a large amount of flushed sediment may be deposited downstream of the dam and create some negative impacts. As shown in Figure $7 \mathrm{a}$, the discharge is less than $200 \mathrm{~m}^{3} / \mathrm{s}$ after $8 \mathrm{~h}$, but it can help wash the released sediment through the downstream fluvial system. For comparison, we also determined that the operators may practice flushing by using $5 \times 10^{6} \mathrm{~m}^{3}$ of water (about the present storage capacity of the Tapu reservoir) in May every year regularly.

Based on the above descriptions, four scenarios are investigated in this study.

1. If the volume of 10-day inflow is greater than $30 \times 10^{6} \mathrm{~m}^{3}$ in May or June, the reservoir simulation model will start to simulate reservoir operation with flushing for $30 \mathrm{~h}$.

2. If the volume of 10-day inflow is greater than $18 \times 10^{6} \mathrm{~m}^{3}$ in May or June, the model will start to simulate reservoir operation with flushing for $8 \mathrm{~h}$.

3. Consume $5 \times 10^{6} \mathrm{~m}^{3}$ of water for flushing in May every year.

4. Apply the reservoir simulation model only to simulate reservoir operation without flushing operation.

Assume that the historical sequential data of outflow water discharge and water level at the dam from 1961 to 1996 are repeatable in the future and used as the input of the models, and that there is $44500 \mathrm{~m}^{3}$ inflow of sediment per year. In addition, inflow sediment may distributed and deposits may be eroded uniformly on the reservoir bed along the simulation domain. Applying the reservoir simulation model with the sediment flushing model, the updated elevation-storage curve, overflow rate and water deficit rate, flushing efficiency can be calculated and analysed. In Table III, simulated results are listed in the 10-day period for shortage index (SI), overflow rate and water deficit rate for these four scenarios. Based on the sequential inflow data for the next 36 years, cumulative flushed sediment volume and cumulative water usage for flushing are calculated when each flushing event occurs under these four different scenarios. The results for scenarios 1 and 2 are listed in Table IV(a and b). The flushing efficiency (FE) for each scenario is also presented in Table III. According to the simulated results under these four scenarios, the following are analysed and discussed.

1. Scenario 1. The overall flushing efficiency is $0.23 \%$ (Table III). However, if the flushed sediment is deposited downstream within the fluvial system and creates environmental impacts, this flushing operation may be needed. In the 36-year simulation period, only eight flushing events are practiced and operated about every 4 years (Table III). 
Table III. Simulated results for different scenarios

\begin{tabular}{|c|c|c|c|c|c|c|c|c|c|}
\hline & A & $\mathrm{B}$ & $\mathrm{C}$ & $\begin{array}{c}\text { Number of } \\
\text { flushing } \\
\text { events }\end{array}$ & $\begin{array}{l}\text { Shortage } \\
\text { index (SI) }\end{array}$ & $\begin{array}{l}\text { Overflow } \\
\text { rate }^{\mathrm{a}}(\%)\end{array}$ & $\begin{array}{c}\text { Water } \\
\text { deficit } \\
\text { rate }^{\mathrm{b}}(\%)\end{array}$ & $\begin{array}{c}\text { Water } \\
\text { usage } \\
\times 10^{6}\left(\mathrm{~m}^{3}\right)\end{array}$ & $\begin{array}{l}\text { Flushing } \\
\text { efficiency } \\
(\mathrm{Fe})(\%)\end{array}$ \\
\hline Scenario 1 & 1241 & 54 & 1 & 9 & 0.68 & $80 \cdot 1$ & 0.9 & $257 \cdot 27$ & $0 \cdot 23$ \\
\hline Scenario 2 & 1241 & 54 & 0 & 18 & $0 \cdot 30$ & $77 \cdot 8$ & 0.6 & $401 \cdot 39$ & 0.56 \\
\hline Scenario 3 & 1219 & 67 & 10 & 36 & 0.68 & $80 \cdot 8$ & 1.5 & $540 \cdot 01$ & 0.28 \\
\hline Scenario 4 & 1240 & 52 & 4 & 0 & 0.51 & $81 \cdot 3$ & 0.8 & 0 & 0.0 \\
\hline
\end{tabular}

A, the number of days when water stage is above upper limit in 10-day period.

$\mathrm{B}$, the number of days when water stage is between upper limit and lower limit in 10-day period.

$\mathrm{C}$, the number of days when water stage is below lower limit in 10-day period.

a Outflow rate: accumulative amount of water outflow/accumulative amount of water inflow.

${ }^{b}$ Water deficit rate: accumulative amount of water deficit/ accumulative amount of water requirement.

2. Scenario 2. Compared with other scenarios, the simulated results listed in Table III show that the lowest overflow rate and water deficit rate can be obtained. It is also found that this scenario has lowest shortage index $(\mathrm{SI}=0.30)$ and highest flushing efficiency $(\mathrm{FE}=0.56 \%)$. No water level controlled during flushing has to drop down below the lower limit of the operation rule curves through the simulation period $(C=0$ in Table III). Furthermore, its shortage index is even less than that in scenario 4 with no flushing operation. This is because flushing can increase storage capacity, and the increased storage makes reservoir operation more efficient. The simulated results (Table III) show that the scheduling of yearly operation is about 2 years on average.

3. Scenario 3. This case has the highest shortage index $(\mathrm{SI}=0 \cdot 68)$. Therefore, it is not an efficient way to practice flushing every year in the Tapu reservoir, even though a relatively small amount of water is used.

4. Scenario 4. In this case, there is no water used for flushing. However, the shortage index is not the lowest among all cases because inflow sediments keep depositing along the reservoir, decreasing the storage capacity as time passes.

Based on the above analyses from simulated results, scenario 2 has the lowest values of shortage index and overflow rate, and has the highest value of flushing efficiency. In the operation of scenario 2, after flooding recedes all gates have to be closed to refill the reservoir immediately, so that it may reduce the risk of insufficient supply for demand in the immediate future. Nevertheless, high concentration of sediment during flushing can release a large amount of sediment downstream of the dam, and it may create some negative environmental impacts. Thus, scenario 1 may be considered as an alternative for washing out sediment deposits downstream of the dam. Therefore, based on the optimal new flushing operating rule curves (F2 shown in Figure 9b), the operators may practice flushing by scheduling operation within an interval of every 2 or 4 years for the Tapu reservoir.

\section{CONCLUSION}

1. A reservoir simulation model is devised and coupled with the sediment-flushing model to consider sediment desiltation by flushing operation. The reservoir simulation is based on the continuity of reservoir inflow and storage. A set of flushing operation rule curves, optimized by using the genetic algorithm, can be determined to meet the needs of water usage for water supply as well as for flushing sediment. The sediment-flushing model simulates the water-surface profile along the reservoir during drawdown operation and estimates the amount of flushed sediment volume for updating the reservoir elevation-storage curve. The models were 
applied to the Tapu reservoir and demonstrated that it is suitable and successful for simulating water supply and water usage for flushing. A rational and riskless scheduling of flushing operation has been obtained. The best timing of flushing operation would be in May or June yearly.

2. Based on the investigation of four scenarios by adopting the event on 11 June 1997 as a typical case of flushing operation in the Tapu reservoir, it is found that if flushing is terminated just after the end of the flood recession period to refill the reservoir, simulation results of scenario 2 present the lowest value of the shortage index (SI) and highest value of flushing efficiency (FE). The scheduling of yearly operation is about every 2 years in May or June. However, it may be necessary to release more water containing a lower sediment concentration in order to remove sediment deposited downstream during the flushing period, in which case scenario 1 (operated every 4 years) may be considered as an alternative for removing sediment deposited downstream of the dam. Instead of flushing every year as operated in scenario 3 , therefore, the flushing schedule for the Tapu reservoir is suggested to be set within an interval of every 2 or 4 years in May or June.

3. Although yearly timing is suggested for sediment flushing in May or June, it may be opportunistic to flush sediment during a typhoon, which may happen in June through to October in Taiwan. However, technically the path or rainfall amount in a typhoon are not easily predictable, which means that there is higher risk to refilling the reservoir after flushing.

\section{ACKNOWLEDGEMENTS}

This paper is based partially on work supported by the Water Resource Bureau, R.O.C. (Grant No. 88EC2B37 0019). We greatly appreciate the former Chairman Dr S.K. Hsu and Division Director Hsieh Cheng-Daw of WRB for their support and suggestions.

\section{REFERENCES}

Chang FJ, Chen L. 1998. Real-coded genetic algorithm for rule-based flood control reservoir management. Water Resources Management 12(3): $185-198$.

Chang FJ, Lai JS. 1999. Investigation on Reservoir Sediment Flushing and Capacity Preservation Techniques with Physical Model Study (III). Report No. 322, Hydrotech Research Institute, National Taiwan University. (In Chinese.)

Chang LC, Chang FJ. 2001. Intelligent control of modeling of real time reservoir operation. Hydrological Processes 15(9): 1621-1634.

Chien N, Wan Z. 1998. Mechanics of sediment transport. American Society of Civil Engineers Press: Reston, VA.

Goldberg DE. 1985. Optimal Initial Population Size for Binary-coded Genetic Algorithms. TCGA Report No. 85001, University of Alabama: Tuscaloosa, AL.

Goldberg DE. 1989. Genetic Algorithms in Search, Optimization and Machine Learning. Addison Wesley: Reading, MA.

Grefenstette JJ. 1986. Optimization of control parameters for genetic algorithms. IEEE Transactions on Systems, Man, and Cybernetics SMC-16(1): 122-128.

Hsu SK. 1995. Shortage indices for water-resources planning in Taiwan. Journal of Water Resources Planning and Management, American Society of Civil Engineers 121(2): 119-131.

Hydrologic Engineering Center. 1966. Reservoir Yield, Generalized Computer Program 23-J2-L245. US Army Corps of Engineers: Davis, CA.

Hydrologic Engineering Center. 1975. Hydrologic Engineering Methods for Water Resources Development, Vol. 8, Reservoir Yield. US Army Corps of Engineers: Davis, CA.

Hydrologic Engineering Center. 1993. HEC-6 Scour and Deposition in Rivers and Reservoir User's Manual. US Army Corps of Engineers: Davis, CA.

Lai JS, Shen HW. 1995. An experimental study on reservoir drawdown flushing. International Journal of Sedimentary Research 10(3): 19-37.

Lai JS, Shen HW. 1996. Flushing sediment through reservoirs. Journal of Hydraulic Research 34(2): 237-255.

Morris GL, Fan J. 1998. Reservoir Sedimentation Handbook. McGraw-Hill: New York.

McKinney DC, Lin MD. 1994. Groundwater optimization using genetic algorithms. Water Resources Research 30(6): 1897-1906.

Oliveira R, Loucks DP. 1997. Operating rules for multireservoir systems. Water Resources Research 33(4): 839-852.

Schaffer JD, Caruana RA, Eshelman LJ, Das R. 1989. A study of control parameters affecting online performance of genetic algorithms for function optimization. In Proceedings of the Third International Conference on Genetic Algorithms, Schaffer JD (ed.). Morgan Kaufmann: San Mateo, CA; 51-60. 
SRL. 1979. Reservoir Sedimentation. Sediment Research Laboratory of Tsinghua University and Northwest Institute of Hydrotechnical Research, Water Conservancy and Electric Power Press: 372 pp. (In Chinese.), Beijing, China.

Shen HW, Lai JS. 1996. Sustain reservoir useful life by flushing sediment. International Journal of Sedimentary Research 11(3): 10-17. Simpson AR, Dandy GC, Murphy LJ. 1994. Genetic algorithms compared with other techniques for pipe optimization. Journal of Water Resources Planning and Management 120(4).

Wang QJ. 1991. The genetic algorithm and its application to calibrating conceptual rainfall-runoff models. Water Resources Research 27(9): $2467-2471$. 